\title{
Hybrid anaerobic baffled reactor for treatment of desizing wastewater
}

\author{
*R. R. Liu; Q. Tian; B. Yang; J. H. Chen \\ Department of Environmental Science \& Engineering, DongHua University, 2999 North Renmin Road, Songjiang \\ district, Shanghai 201620, China
}

Received 21 June 2009; $\quad$ revised 27 July 2009; accepted 18 August 2009; available online 1 December 2009

\begin{abstract}
Polyvinyl alcohol-containing desizing wastewater discharged within final textile wastewater has a great impact to the environment due to its poor biodegradability. An improved lab-scale hybrid anaerobic baffled reactor was developed to treat desizing wastewater. The modification was achieved by increasing the height of hybrid anaerobic baffled reactor and application of proper effluent recycle enabled to increase the ability of entrapping microbe-rich small particles in the reactor and prompted the formation of granules. The significant difficulty in hybrid anaerobic baffled reactor operation is the slow start-up procedure, which is crucial to the overall polyvinyl alcohol-containing desizing wastewater treatment. Therefore, the ability of a hybrid anaerobic baffled reactor, treating desizing wastewater, to achieve a prompt start-up was studied at lab-scale. Results showed that inoculated with anaerobic granular sludge and adoption of effluent recycle during start-up, the system demonstrated a good performance of polyvinyl alcohol removal efficiency (above 17.2 \%) and satisfactory stability of pH and alkalinity in effluent (range around 7.4-8.0 and 700-920 $\mathrm{mg} / \mathrm{L}$, respectively) and the sludge appeared obviously granulation. Thus, the prompt start-up was achieved after 60 days. The start-up strategy used for this process has achieved its goals by creating an active microbial population. The improved lab-scale hybrid anaerobic baffled reactor proved to be an efficient reactor configuration for the treatment of desizing wastewater, which favored the prompt start-up of hybrid anaerobic baffled reactor. The results also provide evidence to modify the design of anaerobic baffled reactor to improve reactor performance.
\end{abstract}

Keywords: Desizing wastewater; Granular sludge; Hybrid anaerobic baffled reactor; Polyvinyl alcohol; Start-up

\section{INTRODUCTION}

A typical textile processing consists of desizing, scouring, bleaching, mercerizing and dyeing operations (EPA, 1997; Dos Santos et al., 2006a; Gharbani et al., 2008; Kumar et al., 2009). The desizing wastewater, the effluent from desizing operation, contributes approximately $50 \%$ of the organic load in the total textile wastewater (Schlüter, 1990; Hickmann, 1993; Feitkenhauer, 2003). A wide range of contaminants in desizing wastewater are from the sizes applied to cotton or synthetics to aid the process of weaving. The typical sizes include starch, polyvinyl alcohol (PVA), polyacrylate and carboxymethyl cellulose (Treffry-Goatley et al., 1983; Chen et al., 1997; Kumar et al., 2009), among them, chemical size of PVA is widely used in the warp sizing process due to its excellent film strength, flexibility, wearability, adhesiveness and chemical durability. As a common refractory organic matter, one gram of PVA is an equivalent of 0.016 biochemical oxygen demand (BOD-) or 1.6 chemical oxygen demand (COD), its BOD/COD is low to 0.01,

凶*Corresponding Author Email: rongrongair@163.com Tel.: +8621 6779 254; Fax: +8621 67792522 indicating the poor biodegradability (Matsumura et al., 1993; Yu et al., 1996). As a consequence, treatment and disposal of PVA-containing desizing wastewater is presently one of the serious environmental problem contributors.

A considerable amount of research work has focused on biodegradation of PVAusing special microorganisms and enzymes. However, there is a long way to go before the full-scale treatment process involved in these special microorganisms and enzymes becomes practical. In order to comply with the stringent COD discharge standard and requirement of energy saving and emission reduction in textile industry, anaerobic process becomes an attractive technology for treating desizing wastewater (Babel et al., 2008). This process takes advantages of microorganisms involved in the anaerobic digestion process and their strong tolerance to high concentration inhibitory organics and unfavorable environmental stresses. Many anaerobic reactors have been applied to treat wastewater (Banu et al., 2007; Behera et al., 2007; Juang and Chiou, 2007) and the anaerobic baffled reactor (ABR) has several 
advantages such as simple design, low energy consumption, high stability for shocking and loading and high treatment efficiency over other ones (Barber and Stuckey, 1999). The ABR was initially developed at Stanford University, it can be described as a series of up-flow anaerobic sludge blanket reactors (UASBs). The ABR uses a series of vertical baffles to force the wastewater to flow under and over them as it passes from inlet to outlet, the wastewater can come into intimate contact with a large amount of active biomass, while the effluent remains relatively free of biological solids (Wang et al., 2004; Gopala Krishna et al., 2009). Moreover, the ABR features in separating acidogenesis and methanogenesis longitudinally down the reactor and enhancing reactor stability. Due to the divided configuration which keeps the biomass in the reactor for a long period of time independent of the hydraulic retention time (HRT), the ABR has potential to cultivate special PVA-decomposing microorganisms and retain them in the reactor to obtain efficient operation. Hence, it will show considerable potential for PVA-containing desizing wastewater treatment.

Prompt start-up is essential for the highly efficient operation of ABR, due to slow growth rates of anaerobic microorganisms, especially methanogens, establishment of the most suitable microbial population is critical to the prompt start-up of ABR. Disadvantages of traditional ABR include the requirement of building shallow reactor to maintain acceptable liquid and gas up-flow velocities (Barber and Stuckey, 1999) which can lead to bacterial washout and delay start-up of the reactor. In addition, potential problems can arise during start-up as a result of plug-flow characteristics, the accumulation of volatile fatty acid (VFA) and low $\mathrm{pH}$, exposition sensitive bacteria in front compartments to toxic levels of inorganic and organic compounds in the high strength feeding wastewater. To overcome these difficulties, some approaches such as low organic loading rate (OLR), feed dilution, periodic feeding and effluent recycling have been recommended (Barber and Stuckey, 1999; Skiadas and Lyberatos, 1998), but they may not be the best solution to the prompt start-up of ABR because compartmentalised structure of ABR bringing with another problems such as nutrient limits in the final compartment and elimination of phase separation. In order to stabilize ABR during start-up by establishment of the most suitable microbial population and eliminate disadvantages of traditional ABR, a novel modification was achieved by increasing the height of hybrid anaerobic baffled reactor (HABR) in this study, which was designed to increase the ability of entrapping microbe-rich small particles in the reactor. In addition, proper effluent recycle was also applied to prompt the formation of granules. Effluent recycle might eliminate phase separation in traditional ABR, but when the height of HABR was increased, the problem may disappear and full phase separation is still to be discovered.

Based on the previous studies and the above discussion, the improved HABR was applied to treat real desizing wastewater after inoculated with commercial anaerobic granular sludge in this study. The objectives were to examine the prompt start-up and the feasibility of lab-scale HABR on treatment of desizing wastewater after modification, in terms of evaluation of removal of PVA, variation of $\mathrm{pH}$, alkalinity and VFA and biomass analysis of anaerobic granular sludge. The research work was performed at Donghua University in 2008.

\section{MATERIALS AND METHODS \\ Configuration of $H A B R$}

The HABR had a dimension of $15 \mathrm{~cm}$ wide, $62 \mathrm{~cm}$ long and $100 \mathrm{~cm}$ high. It was constructed from perspex, with a valid volume of $79.05 \mathrm{~L}$. The reactor was divided into four equal compartments, which incorporated a solids settling chamber after its final compartment. Between the two final compartment and the solids settling chamber there was a $5.5 \mathrm{~cm}$ wide recycle chamber in which inner recycle occurred from it to the first compartment. The compartment was equipped with sampling ports that allowed biological solids, gas and liquid samples to be withdrawn. Fig. 1 shows a schematic diagram of the HABR.

The HABR was operated under mesophilic conditions (32 $\pm 1{ }^{\circ} \mathrm{C}$ ), HRT was $168 \mathrm{~h}$. The influent was adjusted using a variable speed peristaltic pump (Model BT-001, Zhixin, CN), the flow rate was $0.48 \pm 0.01 \mathrm{~L} / \mathrm{h}$. Industrial peristaltic pumps (Model PP6 , SCMI, CN) was used to control effluent recycle velocity $(4.87 \pm 0.13 \mathrm{~m} / \mathrm{h})$ to the reactor.

\section{Wastewater characteristics}

The feed used in this study was desizing wastewater collected from a dying and finishing plant at Chuzhou in Anhui, P. R. China. The raw wastewater composition was as follows: COD $10000 \sim 13520 \mathrm{mg} / \mathrm{L}$, alkalinity (as $\left.\mathrm{CaCO}_{3}\right) 10000 \sim 17000 \mathrm{mg} / \mathrm{L}, \mathrm{BOD}_{5} 1500 \sim 2192 \mathrm{mg} / \mathrm{L}$, 


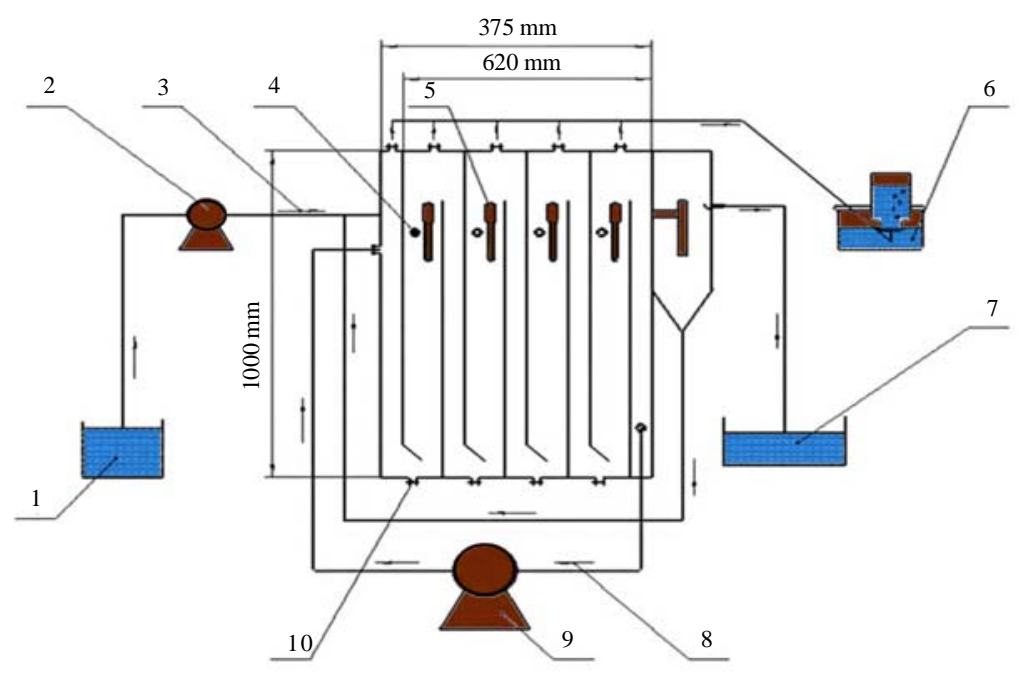

Fig. 1: Schematic diagram of a hybrid anaerobic baffled reactor ((1) Feed tank, (2) peristaltic pump, (3) influent, (4) supernatant sampling port, (5) temperature regulator, (6) biogas holder, (7) effluent, (8) wastewater recycle, (9) industrial peristaltic pumps, (10) sludge sampling port)

PVA $1000 \sim 3000$ mg/L, suspended solid (SS) 5000 $7056 \mathrm{mg} / \mathrm{L}, \mathrm{pH} 12 \sim 14$.

\section{Inoculated sludge}

The HABR was inoculated with anaerobic granular sludge offered by a company of Yixing in China. Characteristics of inoculated sludge were: average particle size $3 \sim 5 \mathrm{~mm}$, sedimentation velocity $23.40 \pm 0.60 \mathrm{~m} / \mathrm{h}$, total suspended solid (TSS) $16.05 \pm$ $0.40 \mathrm{~g} / \mathrm{L}$, volatile suspended solid (VSS) $12.02 \pm 0.30 \mathrm{~g} /$ L, VSS/TSS $72.85 \pm 1.82 \%$.

\section{Analytical methods}

PVA was measured at $690 \mathrm{~nm}$ in spectrophotometer (Model DR 2800, HACH, USA) (Joseph, 1961). pH was measured with a $\mathrm{pH}$ meter, type PHSJ-4A Leici (made in Shanghai). Total alkalinity was measured with titrimetric method proposed by Dilallo and Alberton (1961). In this method, the samples were titrated with $0.1 \mathrm{~N}$ of standard sulphuric acid solution to $\mathrm{pH} 3.5$ from 5.3. Samples of bulk liquid from the reactors were analyzed for the levels of VFAs. Acetate, propionate and butyrate were measured using a gas chromatography (Model Hewlett-Packard 5890A, Palo Alto, USA) with a flame ionization detector. Mean and the standard deviation value of experimental data were calculated from three duplicate samples.

\section{Scanning electron microscope (SEM)}

Sludge samples were taken from each compartment of the reactor after the start-up and the biomass examined by SEM. Samples were first fixed for $4 \mathrm{~h}$ at room temperature with $2.5 \%(\mathrm{w} / \mathrm{v})$ glutaraldehyde in sorenson phosphate buffer and dehydrated through a graded series of water-ethanol mixtures (10\%, $25 \%, 50$ $\%, 75 \%, 90 \%, 100 \%)$. The samples were brought to equilibrium in each mixture for $10 \mathrm{~min}$ and finally dried by the frozen drying method before sputter-coating with gold particles. The samples were then examined in a scanning electron microscope (Model JSM-5600LV, Shimazu, JAP). Micrographs were produced at magnifications between 10 and 10,000 times.

\section{RESULTS AND DISCUSSION}

PVA removal

During the initial start-up period, the HRT was kept constant for $168 \mathrm{~h}$ with lower volumetric loading and the wastewater was diluted to the required strength with addition of glucose and increased amount of PVA. The removal of PVA was investigated: the PVA removal rate was about $50.1 \pm 1.5 \%$ with the influent containing a nominal $500 \mathrm{mg} / \mathrm{L}$ PVA. With the decrease of glucose and the increase of desizing wastewater, nominal influent PVA concentration increased from $500 \mathrm{mg} / \mathrm{L}$ to $3000 \mathrm{mg} / \mathrm{L}$ during the 60 -day operation period and the PVA removal decreased from $50.1 \%$ to $17.2 \%$. The PVA concentration profile in the HABR was monitored at the end of each load. PVA removal occurred throughout the entire length of the reactor as shown in Fig. 2. This Figure shows that the removal of PVA began decreasing with the increase of PVA concentration. In the beginning, the good removal of PVA probably due to 


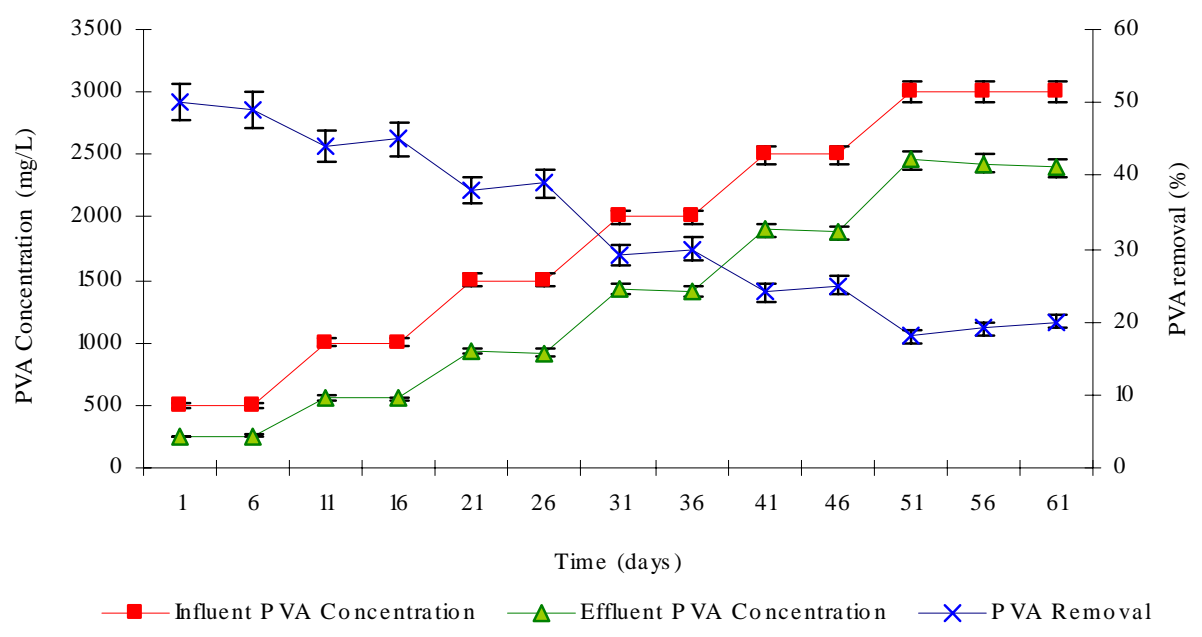

Fig. 2: Concentrations variation and removal rate of PVA over time

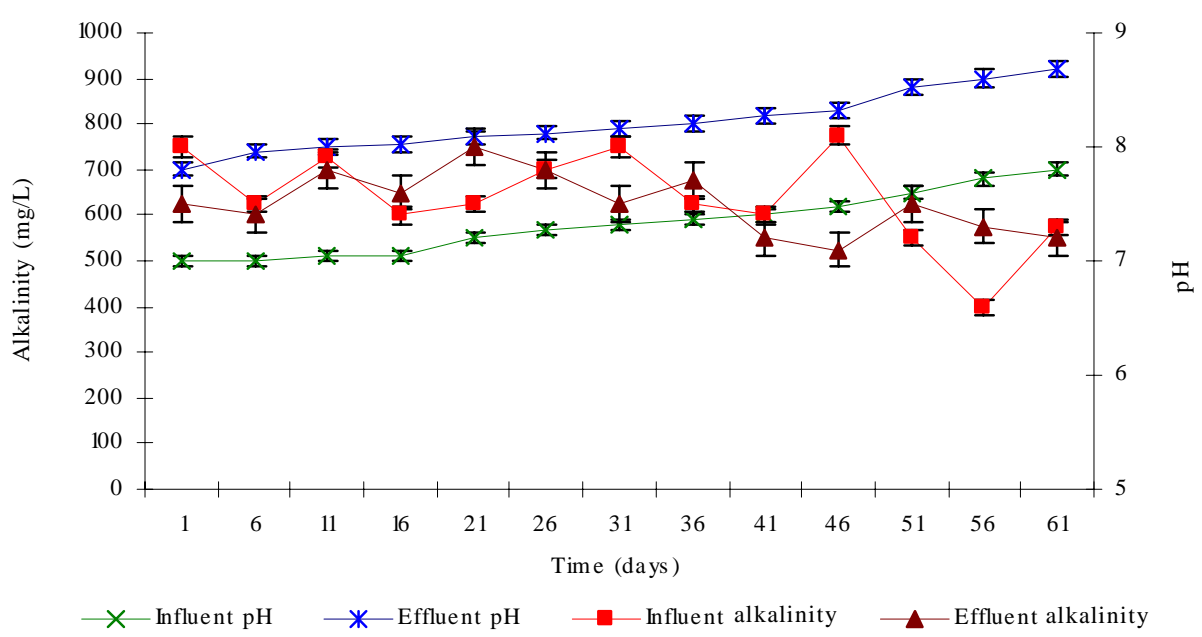

Fig. 3: Variation of $\mathrm{pH}$ and alkalinity over time

the usage of granular sludge to shorten the acclimatization period by sustaining high microbial activity or the absorption function of granular sludge. With the passing of the operation time, the removal of PVA decreased, which may due to the increase of PVA load and the partly desorption of PVA from the granules after the surface potential actived adsorption sites were saturated with PVA.

pH and alkalinity

Proper $\mathrm{pH}$ and alkalinity are of key importance for the prompt start-up of HABR. In this study, the $\mathrm{pH}$ of influent was corrected between 6.5 and 8.0 using $1 \mathrm{M}$ $\mathrm{H}_{2} \mathrm{SO}_{4}$ and alkalinity was adjusted deliberately higher than normal $(\mathrm{pH}<8.2$ ) (Wolfe, 1979). Influent $\mathrm{pH}>8.2$ did not try to avoid the inhibition of methanogenic bacteria, but the specific mechanism of granule formation with higher alkalinity is unclear. In this study, higher alkalinity applied during start-up provided buffering in the system to prevent the souring of the reactor, which may inhibit proliferation of methanogenic bacteria. When influent was relatively abundant with calcium and magnesium, the increased influent alkalinity (mainly from carbonate) would result 
in forming crystals, which can be used as "nuclei” during the process of formation of granular sludge and speed up formation of granular sludge. Therefore, prompt start-up of the HABR was achieved in the study. At the end of the formation of basic particles, proper low alkalinity was done to improve specific methanogenic activity of granular sludge. At the same time, effluent recycle was adopted to maintain $\mathrm{pH}$ and alkalinity at a stable level. With the above mentioned strategies, souring did not occur in the whole start-up period. It was indicated $\mathrm{pH}$ and alkalinity were important parameters to measure the stability of the reactor. When the reactor was operated efficiently, effluent $\mathrm{pH}$ and alkalinity were relatively stable. The variation of $\mathrm{pH}$ and alkalinity are shown in Fig. 3. The effluent $\mathrm{pH}$ varied between 7.4 and 8.0 and alkalinity varied between 700 and $920 \mathrm{mg} / \mathrm{L}$.

VFA

VFAs are the intermediate products in the anaerobic digestion process. The accumulation of VFAs might result in lower $\mathrm{pH}$ and even the failure of the anaerobic digestion process. The concentration of VFA in the anaerobic reactor coincided with the activity of methanogenic bacteria and stability of the reactor operation conditions, while higher VFA concentration would inhibit the normal growth of methanogenic bacteria. Therefore, VFA is a very important control parameter during the operation of the reactor. The profiles of VFAs in different compartments at organic loading rates of $1.92 \mathrm{~kg} \mathrm{COD} / \mathrm{m}^{3} /$ day are shown in Fig. 4. It can be seen that acetate was the main intermediate product of acidogenic degradation of desizing wastewater in the HABR. Acetate and butyrate are considered to be optimal fermentation products for the methanogenic phase (Zoetemeyer et al., 1982; Ren et al., 1997; Azbar et al., 2001). Propionate has been reported to accumulate readily in anaerobic reactors (Tartakovsky and Guiot, 1997; Shin et al., 2001). Hence, the formation of butyrate is desirable over propionate, because it is easily metabolised to methane via acetate. The metabolic pathway of desizing wastewater fermentation in the HABR maybe favored acetate and butyrate production. The highest VFA concentration was found in the second compartment. The VFA data demonstrated that hydrolysis and acidogenesis were the main biochemical activities occurring in the first two compartments. The total VFA concentrations decreased longitudinally down the reactor from compartment 2 . The turn of total VFA concentration is, compartment $2>3>4$, but compartment $1<2$. However, the methanogenesis appeared to be dominant in the third and fourth compartments, the investigation indicates that a near plug-flow hydraulic regime might have taken place in the HABR system. The VFA concentration in each compartment was around $300 \mathrm{mg} / \mathrm{L}$, this maybe caused by the application of effluent recycle and acclimatization of methanogenic bacteria which partly began to degrade organic acid. All these observations suggest that the system promoted a systematic selection and concentration of specific microorganisms in the different compartments in such a manner as to bring about phase biodegradation.

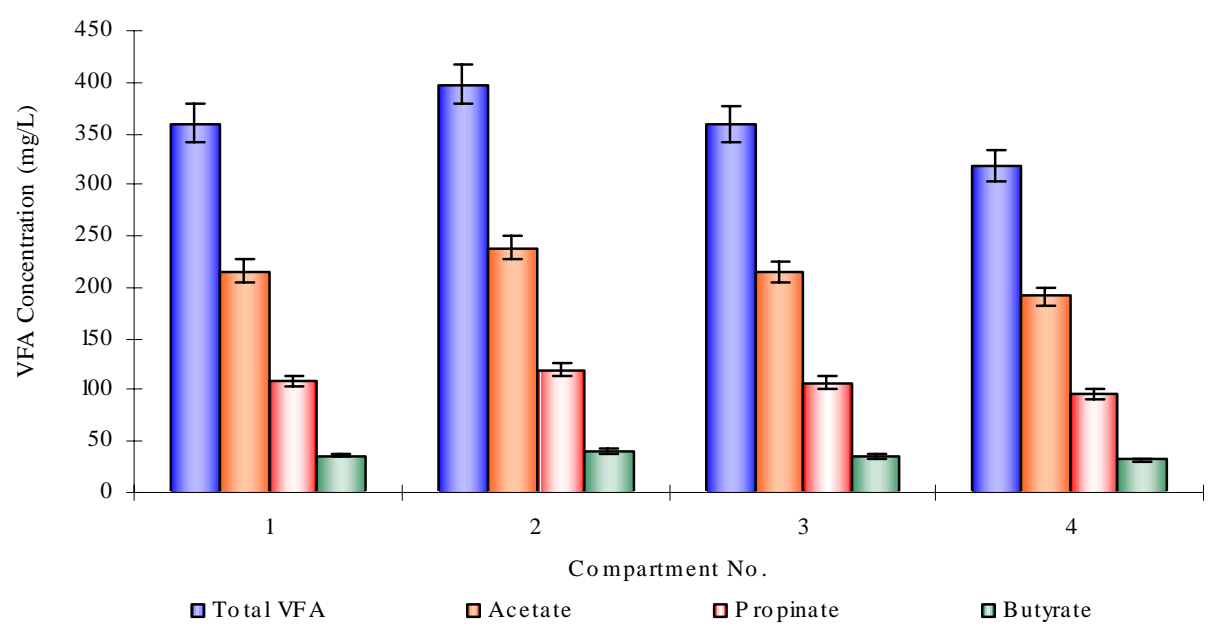

Fig. 4: VFA profiles in different compartments 

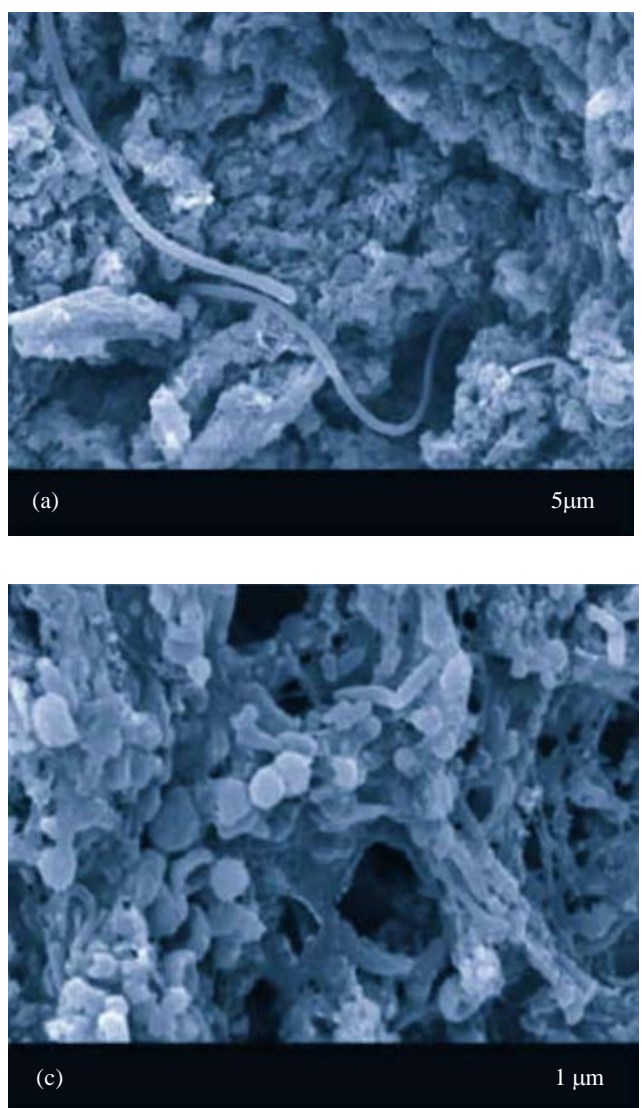
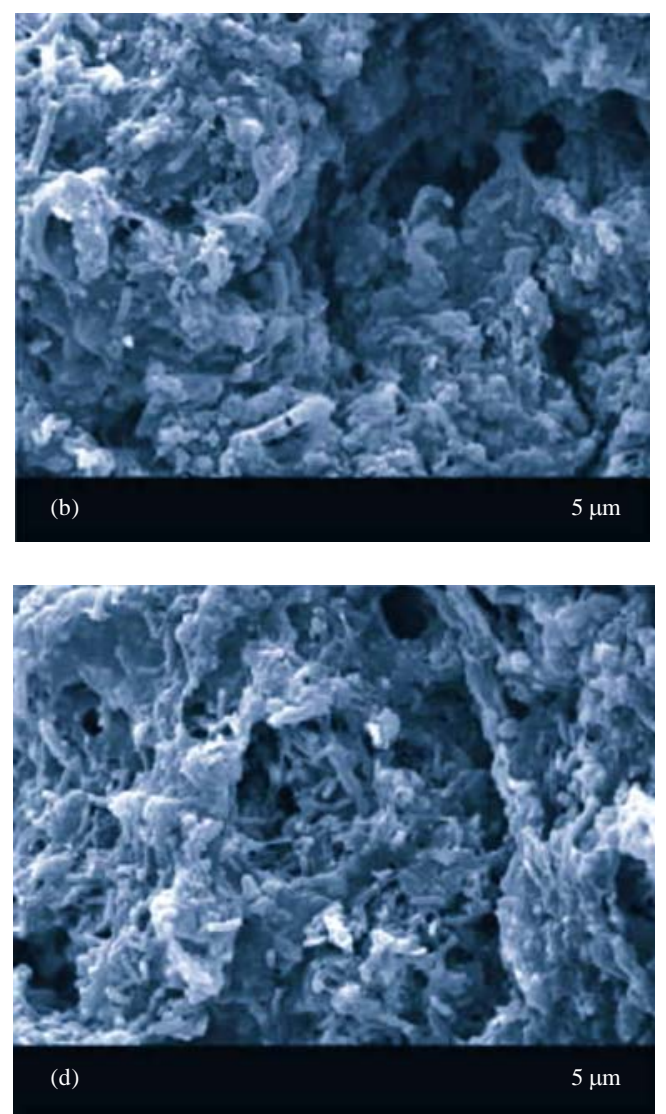

Fig. 5: Scanning electron photomicrographs showing the bacterium of granular sludge ((a) Short rod-shaped and filamentous bacteria in Compartment 1, (b) A mixed culture: methanogenic bacteria, including bacilli and cocci in Compartment 2, (c) Methanococcus and Methanobacterium in Compartment 3, (d) Methanobrevibacter in Compartment 4)

\section{Microbial population distribution in the reactor}

Some studies have focused on the microbial population distribution in the ABR, the results showed partly disparity of microbial population distribution under different experimental conditions (Sallis and Uyanik, 2003). In this study, the inoculated sludge was black. The sludge appeared obviously granulation after 60 days and the surface of granular sludge in each compartment of the reactor was black. The SEM images of the granule sludge from compartment 1 to 4 are given in Fig. 5 a-d, respectively. Different bacterial morphologies were observed within the HABR. Compartment 1 had various microorganisms, predominated by short rod-shaped and filamentous bacteria, as illustrated in Fig. 5a. Compartment 2 had no preponderant bacteria, the morphotype observed were bacilli and cocci, maybe they were similar to methanogenic bacteria. In compartment 3 of the reactor, various cocci and rod-shaped bacteria were observed. The cocci bacteria resemble species of the methanococcus genus and rod-shaped bacteria resemble species of the methanobacterium genus. In compartment 4 , the observed preponderant morphotype were short rod-shaped bacteria, a typical characteristic of the methanobrevibacter. These results showed partly different from others abundant bacilli and cocci existed in compartment 3 and 4, while few filament appeared; maybe due to the inoculation of granular sludge and application of effluent recycle. Observations from these micrographs suggest that microbial selection and zoning are encouraged inside the HABR, the different bacterial groups developed under most favorable conditions (Wang et al., 2004).

\section{CONCLUSION}

The results of the studies in this paper lead to the following conclusions about the HABR: 
a. Inoculated with the anaerobic granular sludge, the HABR for desizing wastewater treatment achieved a prompt start-up, it is suitable to treat real high-strength desizing wastewater and separation is encouraged by compartmentalisation.

b. During the initial start-up period of HABR, lower volumetric loading was the key for start-up of HABR, PVA removal efficiency varied with the operation of time and PVA had good biodegradation.

c. Proper $\mathrm{pH}$ and alkalinity are of key importance for the prompt start-up of HABR. When the reactor was operated efficiently, effluent $\mathrm{pH}$ and alkalinity were relatively stable.

d. The metabolic pathway of desizing wastewater fermentation in the HABR favored acetate and butyrate production. Acetate and butyrate are considered to be optimal fermentation products for the methanogenic phase

e. Biomass analysis of granulation sludge by SEM after the start-up of HABR indicates that microbial selection and zoning are encouraged inside the HABR.

All the above indicated that an appropriate microbial population has been established and the prompt startup has been achieved. The improved lab-scale HABR proved to be an efficient reactor configuration for the treatment of desizing wastewater favored the prompt start-up of HABR. The results also provide evidence to modify the design of ABR to improve reactor performance. Further work will be carried out to increase the performance of the HABR for treatment of desizing wastewater.

\section{ACKNOWLEDGEMENTS}

The authors wish to thank Zhongde Company for offering the anaerobic granular sludge used in this study. This work was supported by the Innovation Foundation of Donghua University for Ph.D. candidates (BC200828) and Key Discipline Establishment Found of Shanghai Municipal Government (B064).

\section{REFERENCES}

Azbar, N.; Ursillo, P.; Speece, R. E., (2001). Effect of process configuration and substrate complexity on the performance of anaerobic processes. Water Res., 35 (3), 817-829 (13 pages).

Babel, S.; Tang, J.; Pecharaply, A., (2008). Anaerobic codigestion of sewage and brewery sludge for biogas production and land application. Int. J. Environ. Sci. Tech., 6 (1), 131-140 (10 pages).
Barber, W. P.; Stuckey, D. C., (1999). The use of the anaerobic baffled reactor (ABR) for wastewater treatment: A review. Water Res., 33 (7), 1559-1578 (20 pages).

Banu, J. R.; Kaliappan, S.; Yeom, I. T., (2007). Treatment of domestic wastewater using upflow anaerobic sludge blanket reactor. Int. J. Environ. Sci. Tech., 4 (3), 363-370 (7 pages).

Behera, S. K.; Rene, E. R.; Murthy D. V. S., (2007). Performance of up - flow anoxic bioreactor for wastewater treatment. Int. J. Environ. Sci. Tech., 4 (2), 247-252 (6 pages).

Chen, G.; Chai, X.; Yue, P. L.; Mi, Y., (1997). Treatment of textile desizing wastewater by pilot scale nanofiltration membrane separation. J. Membrane Sci., 127 (1), 93-99 (7 pages).

Dilallo, R.; Alberton, O. E., (1961). Volatile acids by direct titration. JWPCF., 33 (4), 356-365 (10 pages).

Dos Santos, A. B.; Bisschops, I. A. E.; Cervantes, F. J., (2006a). Closing process water cycles and product recovery in textile industry: Perspective for biological treatment. In: Cervantes, F. J.; Van Haandel, A. C., Pavlostathis, S.G. (Eds.), Advanced Biological Treatment Processes for Industrial Wastewaters,Vol. 1. International Water Association, London, 298.

EPA, (1997). Profile of the textile industry. Environmental Protection Agency, Washington, USA.

Feitkenhauer, H., (2003). Anaerobic digestion of desizing wastewater: Influence of pretreatment and anionic surfactant on degradation and intermediate accumulation. Enzyme. Microb. Tech., 33 (2-3), 250-258 (9 pages).

Gharbani, P.; Tabatabaii, S. M.; Mehrizad, A., (2008). Removal of Congo red from textile wastewater by ozonation. Int. J. Environ. Sci. Tech., 5 (4), 495-500 (6 pages).

Gopala Krishna, G. V. T.; Kumar, P.; Kumar, P., (2009). Treatment of low-strength soluble wastewater using an anaerobic baffled reactor (ABR). J. Environ. Manage., 90 (1), 166-176 (11 pages).

Hickmann, W., (1993). Environmental aspects of textile processing. J. Soc. Dyers Colour., 109 (1), 32-37 (6 pages).

Joseph, H. F., (1961). Spectrophotometric determination of polyvinyl alcohol in paper coatings. Anal. Chem., 33 (13), 1925-1927 (3 pages).

Juang, D. F.; Chiou, L. J., (2007). Microbial population structures in activated sludge before and after the application of synthetic polymer. Int. J. Environ. Sci. Tech., 4 (1), 119-125 (7 pages).

Kumar, P.; Prasad, B.; Chand, S., (2009). Treatment of desizing wastewater by catalytic thermal treatment and coagulation. J. Hazard. Mater., 163 (1), 433-440 (8 pages).

Matsumura, S.; Kurita, H.; Shimokobe, H., (1993). Anaerobic biodegradability of polyvinyl alcohol. Biotech. Lett., 15 (7), 749-754 (6 pages).

Ren, N.; Wang, B.; Huang, J. C., (1997). Ethanol type fermentation from carbohydrate in high rate acidogenic reactor. Biotech. Bioeng., 54 (5), 428-433 (6 pages).

Sallis, P. J.; Uyanik, S., (2003). Granule development in a split-feed anaerobic baffled reactor. Bioresour. Tech., 89 (3), 255-265 (11 pages).

Schlüter, K., (1990). Oekologische beurteilung von schlichtemitteln. Melliand. Textil. Int., 71, 195-198 (4 pages).

Shin, H. S.; Han, S. K.; Song, Y. C.; Lee, C. Y., (2001). Performance of UASB reactor treating leachate from acidogenic fermenter in the two-phase anaerobic digestion of food waste. Water Res., 35 (14), 3441-3447 (7 pages). 
Skiadas, I. V.; Lyberatos, G., (1998). The periodic anaerobic baffled reactor. Water Sci. Tech., 38 (8-9), 401-408 (8 pages).

Tartakovsky, B.; Guiot, S. R., (1997). Modeling and analysis of layered stationary anaerobic granular biofilms. Biotech. Bioeng., 54 (2), 122-130 (9 pages).

Treffry Goatley, K.; Buckley, C.; Groves, G., (1983). Reverse osmosis treatment and reuse of textile dyehouse effluents. Desalination, 47 (1-3), 313-320 (8 pages).

Wang, J. L.; Huang, Y. H.; Zhao, X., (2004). Performance and characteristics of an anaerobic baffled reactor. Bioresour. Tech., 93 (2), 205-208 (4 pages).
Wolfe, R. S., (1979). Methanogens, a surprising microbial group. Anton. Leeuw., 45, 353-364 (12 pages).

Yu, H.; Gu, G.; Song, L., (1996). Degradation of polyvinyl alcohol in sequencing batch reactors. Environ. Sci. Tech., 17 (11), 1261-1267 (7 pages).

Zoetemeyer, R. J.; van den Heuvel, J. C.; Cohen, A., (1982). $\mathrm{pH}$ influence on acidogenic dissimilation of glucose in an anaerobic digestor. Water Res., 16 (3), 303-311 (9 pages).

\section{AUTHOR (S) BIOSKETCHES}

Liu, R. R., Ph.D. Candidate, Department of Environmental Science and Engineering, DongHua University, Shanghai, China. Email: rongrongair@163.com

Tian, Q., Ph.D., Associate Professor, Department of Environmental Science and Engineering, DongHua University, Shanghai, China. Email: tq2004@dhu.edu.cn

Yang, B., Ph.D., Associate Professor, Department of Environmental Science and Engineering, DongHua University, Shanghai, China. Email: yangbo@dhu.edu.cn

Chen, J. H., Ph.D., Full Professor, Department of Environmental Science and Engineering, DongHua University, Shanghai, China. Email: cjh@dhu.edu.cn

How to cite this article: (Harvard style)

Liu, R. R.; Tian, Q.; Yang, B.; Chen, J., (2010). Hybrid anaerobic baffled reactor for treatment of desizing wastewater. Int. J. Environ. Sci. Tech., 7(1), 111-118. 